\title{
Nutritional Biomarkers for Predicting Pancreatic Beta Cell Failure in Central Obesity
}

\author{
Miftakh Nur Rahman ${ }^{1,2}$, Ajeng Diantini1 ${ }^{1,3}$, Miswar Fattah², Melisa Intan Barliana ${ }^{3,4, *}$ \\ ${ }^{1}$ Department of Pharmacology and Clinical Pharmacy, Faculty of Pharmacy, Universitas Padjadjaran, J1. Raya Bandung Sumedang KM 21, \\ Jatinangor, Indonesia \\ ${ }^{2}$ Prodia Clinical Laboratory, Jl. Kramat Raya No. 150, Jakarta, Indonesia \\ ${ }^{3}$ Center of Excellence in Higher Education for Pharmaceutical Care Innovation, Universitas Padjadjaran, Jl. Raya Bandung Sumedang KM 21, \\ Jatinangor, Indonesia \\ ${ }^{4}$ Department of Biological Pharmacy, Faculty of Pharmacy, Universitas Padjadjaran, Jl. Raya Bandung Sumedang KM 21, Jatinangor, Indonesia \\ ${ }^{*}$ Corresponding author. E-mail: melisa.barliana@unpad.ac.id
}

Received date: Nov 6, 2020; Revised date: Dec 8, 2020; Accepted date: Jan 25, 2021

\section{Abstract}

B ACKGROUND: There is a continuous rise in the prevalence of central obesity and become a pressing health problem in the world. Central obesity followed by many metabolic disorders especially Type 2 Diabetes Mellitus (T2DM). The pathogenesis started from overnutrition signal that force pancreatic beta cells to produce a large number of insulin. Low-grade chronic inflammation that occurred also affects the organs sensitivity against insulin and caused beta cells to compensated this situation and at the end become exhausted and loss its function.

CONTENT: Along compensation mechanism, certain nutrients were support the beta cells to maintain their mass and function to produce insulin. Short chain fatty acids (SCFAs) are gut microbiota fermentation product that act as nutrient and give an advantage to the proliferation and survivability of the beta cells. Zinc ( $\mathrm{Zn})$ also plays an important role in every step of insulin production. Moreover, these nutrients protecting pancreas against inflammation and oxidative stress through certain mechanism. Most of patients with central obesity are unaware of the presence of this disturbance at early stage. Whereas, at molecular level there is a magnitude of SCFAs and $\mathrm{Zn}$ level in the blood that would become an early signal and predict the damage of beta cells.

SUMMARY: Quantification of these two nutrients in the blood expected to provide an early warning tool to maintain insulin adequacy and predict the possibility of beta cell failure in central obesity with promising performance.

KEYWORDS: central obesity, T2DM, SCFAs, Zinc, beta cell failure

Indones Biomed J. 2021; 13(1): 19-26

\section{Introduction}

Obesity has become a pressing health problem worldwide. There is continuously rise in the prevalence of obesity and calculated nearly tripled between 1975 to 2016. The data from World Health Organization (WHO) showed that $13 \%$ of adult population in the world were obese in 2016. (1) Because of its high prevalence, obesity considered as global epidemic.(2) The body mass index is the metric currently use to represent an index of individual fatness. (3) Beyond the body mass index, the fat distribution pattern has a profound influence on cardiometabolic risk. Visceral abdominal fats (VAF) are metabolically active with chronic low-grade inflammation occurred and presents a higher cardiometabolic risk association than the body mass index (BMI).(4)

Abdominal obesity also known as central obesity with the recent global prevalence based on a meta-analysis was $41.5 \%$ which is higher than obesity prevalence.(5) Central 
obesity directly associated with increased VAF and it is also become a potential risk factor for endothelial dysfunction, insulin resistance, Type 2 Diabetes Mellitus (T2DM), and metabolic syndrome.(6) Specifically, previous study showed that central obesity remained a significant predictor T2DM. (7) Interestingly, $43.8 \%$ of previously undiagnosed T2DM patients in Indonesia are with central obesity (8) and once T2DM diagnosed, at least $50 \%$ of pancreatic beta cell mass has decreased and continuously deteriorated along T2DM progression (9). When patients diagnosed at that point, actually it is already late. Hence, beta cell failure early prediction is very crucial before the occurrence of T2DM. The pathophysiology of T2DM is indeed very complex. Various studies are still being conducted to determine the risks and its development. Recent evidence has recognized that the functional mass degradation of beta cells is a common characteristic of both type of Diabetes Mellitus and indicating the core of its pathogenesis. $(10,11)$ It is important to emphasize that diabetes never develops unless beta cells fail to compensate chronic insulin high demand.(12)

The high demand of insulin triggered by obesity due to overnutrition signal. Along this condition, beta cells compensate the high demand of insulin until exhausted and loss their mass and function to produce insulin. Along compensating mechanism, certain nutrients used by beta cells to maintain their mass and function to produce insulin. The nutrients are Short Chain Fatty Acids (SCFAs) as metabolites from gut microbiota and also Zinc (Zn) as micronutrient which is have an important role in the whole process of insulin secretion. Interestingly, recent study showed that serum SCFAs are more associated with metabolic syndrome than fecal SCFAs.(13) In the present review, we deeply explored these blood nutrients potential feature to predict the beta cell health in central obesity based on their concentration changes long before the beta cell failure occurred.

\section{Pathophysiology of Central Obesity to Induce T2DM}

Obesity is defined by WHO as excessive accumulation of body fat that causing abnormalities in energy metabolism. Obesity is characterized by an increase in total body mass and measured by body mass index (BMI) as the most common quantification. BMI has been known to correlate with various morbidity and mortality risks for various populations. The BMI value expressed as obesity in adults based on WHO criteria for the entire world population is $>30 \mathrm{Kg} / \mathrm{m}^{2}$.
But for the Asian population, WHO recommends different values and stratification based on the risk of comorbidity as follows: $\mathrm{BMI} \geq 23 \mathrm{Kg} / \mathrm{m}^{2}$ is expressed as increased risk and $\mathrm{BMI} \geq 27.5 \mathrm{Kg} / \mathrm{m}^{2}$ expressed as high risk.(14)

Obesity is known as a risk factor for T2DM, cardiovascular disease, polycystic ovary syndrome (PCOS), fatty liver, and neoplasia.(15) It is influenced by nutritional factor, physical activity, hormonal system, the aging process, gender, and genetic even in a low frequency interact with lifestyle factors to predispose to the increase of ectopic fat and the development of insulin resistance.(16) Energy surplus from nutrition followed by physical activity levels lead to an increase fat accumulation as subcutaneous adipose tissue (SAT) and visceral adipose tissue (VAT). (17) However, regarding the main function of insulin as a regulator of energy metabolism, it inhibits lipolysis and induce lipogenesis. Insulin concentration is increased in obesity and might act as cause of lipid accumulation overtime as a response for overnutrition status. Excessive lipogenesis lead to a complex metabolism disruption (Figure 1).(15)

The accumulation of visceral abdominal fat (VAF) have an association with metabolic risk factors that are stronger than obesity in body mass index (BMI). Type of obesity which is characterized by a buildup of fat in the abdominal area known as central obesity. Central obesity is measured by waist circumference (WC). The criteria for central obesity in Asian populations except Japanese are $\geq 90 \mathrm{~cm}$ for men and $\geq 80 \mathrm{~cm}$ for women.(18) Abnormalities of VAT accumulation lead to adipocytes hypertrophy which is can turn into adipose tissue dysfunction. Furthermore, adipose tissue dysfunction is caused by chronic inflammation which gradually develops into insulin resistance that will also spreads to liver and muscles with the same mechanism as pro-inflammatory cytokines and free fatty acids distribution through blood vessels.(19)

On the other hand, adipose tissue hypertrophy is one of the contributor to the increase of basal lipolysis in VAT that induce lipo-toxicity and promote the production of inflammatory cytokine and adipocyte secretory such as adipokine.(20) In the pancreas, these effects induce the decrease of amount and capacity of beta cell to secrete insulin and predisposing to the development of T2DM.(15) However, the problem of obesity is an imbalance between energy intake and expenditure, resulting in the accumulation of energy reserves in the form of fat and nutrient sensing failure in metabolic pathways. These failures lead to increase mitochondrial activity which produces excessive energy, endoplasmic reticulum activity, many metabolites 


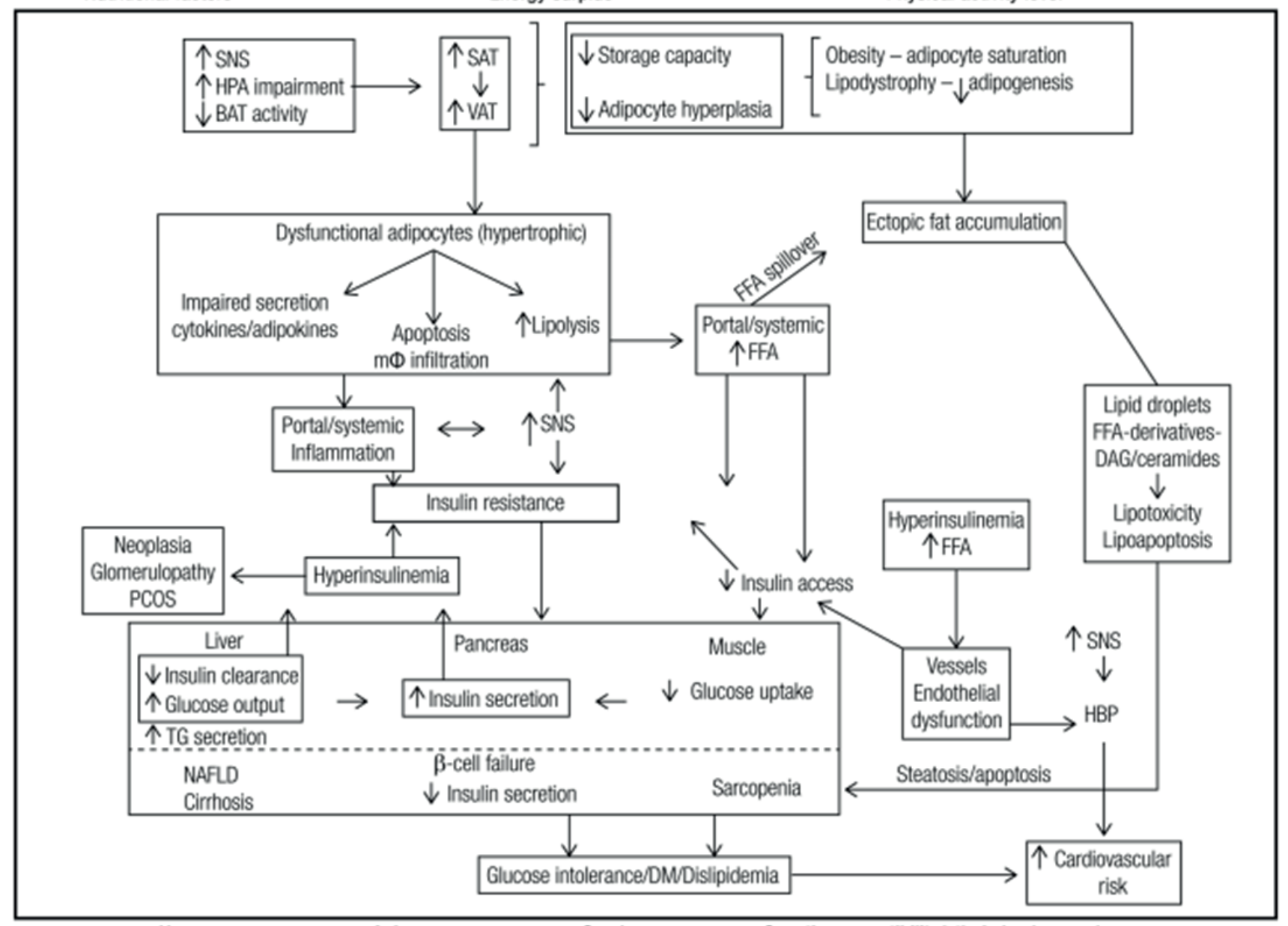

Homones

Aging

Gender

Genetic susceptibility/ethnic background

Figure 1. Summary of obesity pathophysiological mechanism complexity and its association with several metabolic disorders especially beta cell failure as a predisposition for T2DM development.(15) SNS; sympathetic nervous system, HPA; hypothalamus pituitary axis, BAT; beige adipose tissue, SAT: subcutaneous adipose tissue, VAT: visceral adipose tissue, FFA: free fatty acid, NAFLD: non-alcoholic fatty liver disease, TG: triglyceride, DM: diabetes mellitus, PCOS: polycystic ovary syndrome, HBP: high blood pressure. (Adapted with permission from Archive of Endocrinology and Metabolism).

that involves in cell energy cycles, and free radicals in high level. Ultimately, other metabolic pathways that are related will be disrupted and cause systemic inflammation or known as metaflammation. $(21,22)$

One of the most common metabolic disorders which is induced by central obesity is T2DM. More than $40 \%$ of diagnosed T2DM patients are with central obesity.(8) At the beginning, insulin resistance can presence simultaneously with hyperinsulinemia caused by excessive secretion of pancreatic beta cells which is occurred for long periods, and over time, beta cells will deteriorated and totally lost its function.(23) If insulin resistance and hyperinsulinemia persistently happen, it will result in hyperglycemia as a basic character of T2DM. Various variants of the risk of T2DM in healthy subjects are more often due to beta cell failure than insulin resistance even though the two conditions can interact with each other with high complexity.(24) Nutrients excess, for example hyperglycemia reciprocally stimulate beta cell failure and insulin resistance. However, beta cell failure is considered to be more detrimental than insulin resistance. In that condition, insulin secretion is disturbed along with insulin resistance. Insulin will continue to be produced because it continues to receive signals from tissues that require higher concentrations of insulin and this condition can accelerate the progression of T2DM.(25)

Naturally, beta cells have a capability to compensate these conditions, so that their physiological conditions can be achieved again by forming larger beta cells until hyperplasia and hypertrophy occurred and finally causing hyperactivity. But due to inflammatory cytokines that continuously enter the pancreas, over the time, beta cells will undergo apoptosis and hypotrophy which reduce the 
mass of the beta cells themselves. $(25,26)$ Nutrients that got involved in proliferation, anti-inflammation, and insulin synthesis are certainly needed by beta cells in order to maintain their integrity as illustrated in Figure 2.

Adequacy of beta cell function requires the integrity of beta cells which have a critical function in maintaining the balance of insulin demand fluctuations in the human body. The function of beta cells can be measured mathematically using the Homeostasis Model Assessment of Beta Cell Function (HOMA-B) approach obtained from the calculation of fasting insulin concentration $\mathrm{x} 20$ / fasting glucose -3.5 and the results are expressed in percent (\%). Under normal conditions, the blood glucose concentration is controlled within a very narrow range which coordinates with the regulation of insulin secretion and the availability of nutrients especially glucose. The central cause known to damage beta cell function is inflammation that occurs in adipose tissue and spreads to the pancreatic tissue with cytokine mediation, starting from obesity, especially central obesity, insulin resistance and excess fat-containing foods. $(24,27)$

Before T2DM occurs, impaired glucose tolerance in the tissue has begun to present but still reversible to normoglycemia. This condition is known as prediabetes and has a 6 times higher risk of becoming T2DM compared to normoglycemia and has the same complications as diabetes. (28) Thus, interventions at the prediabetes level can reduce the rate of T2DM. One common characteristic found in central obesity before T2DM occurs is hyperinsulinemia and if it lasts for a long time it will develop into beta cell failure. The worse thing, T2DM is not symptomatic at early onset, according to that condition, many patients do not know whether they are suffering T2DM or not. Once diagnosed, actually least $50 \%$ of beta cells were deteriorated and continuously decreased along the disease progression over the time.(9) Therefore, beta cell failure early prediction

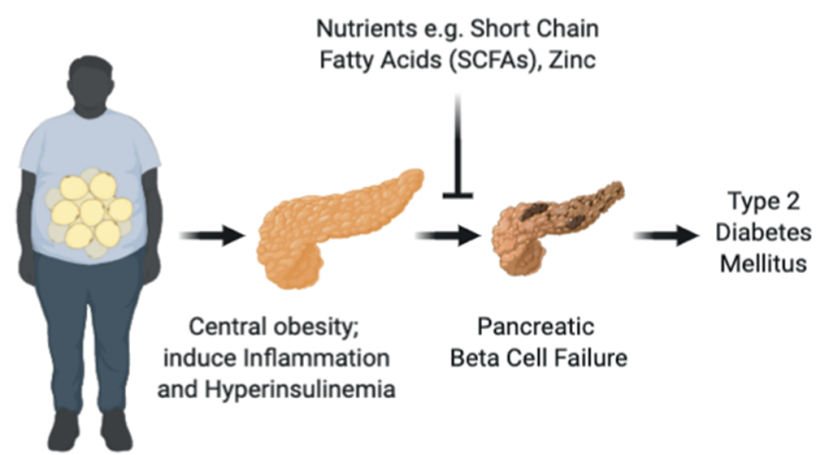

Figure 2. The role of nutrients to maintain beta cells integrity and function in central obesity. become an important thing to hold up the progression of T2DM.(25)

Pathophysiological mechanism of obesity that induce metabolic alteration in fact, already happened in central obesity before the presence of T2DM, including chronic low-grade inflammation, beta cell excessive activity to secrete insulin, and also lipo-toxicity. However, there is nutritional factor that got involved to maintain the adequacy of beta cell mass. The increase in mass of beta cells is also regulated by carbohydrate fermentation products produced by intestinal bacteria, namely SCFA (29) that currently known as nutrient signal ligand and protects beta cells from inflammation (30). Intestinal bacteria indirectly contributed to their host's organs health and linking their interaction through SCFAs.

\section{The Role of SCFAs in Pancreatic Beta Cell Healthy}

SCFAs are fermentation product of intestinal bacteria from dietary fiber that cannot be digested by the human digestive system. SCFAs are classified based on the number of carbon atoms that are not more than six.(31) The majority of SCFAs consists of acetate, propionate and butyrate. The concentration of SCFAs in the intestine varies greatly, depending on the part of the large intestine. But the highest concentration is found in the proximal caecum and colon. The distribution of each type of SCFAs has a difference. For example, butyrate is mostly used as an energy source from colonocytes. Propionate undergoing continued metabolism in the liver, while acetate with high concentrations will be used in various organs so that the concentration of the three types of SCFAs in the blood circulation will be varies.(32) In metabolic function, SCFAs are known to play a role in the physiological and pathological processes of the metabolic syndrome which include obesity.

SCFAs are known to play a role in inhibiting lipolysis that would give a beneficial to reduce lipo-toxicity and improving insulin sensitivity.(13,20,32-34) In addition, SCFAs also act as epigenetic agents involved in the expression of various proteins involved in many metabolic pathways.(32,35,36) Epigenetic mechanisms are heritable changes in gene expression that occur in a cell without any modifications in the DNA sequence.(37) The mechanism of action of SCFAs as epigenetic agents lies in its ability to inhibit the enzyme Histone Deacetylase (HDAC) and activate the enzyme Histone Acetyl Transferase (HAT). Butyrate has the ability to be an HDAC inhibitor in cancer 
cells but can be a HAT activator in healthy cells, regulation of acetylation and deacetylation of histones is part of the mechanism of various metabolic diseases including T2DM.(38)

The association of SCFAs with T2DM shows a variety of potential association that can be applied in monitoring of T2DM development.(31) SCFAs are known as a ligand of nutrient sensor G-Protein Coupled Receptor (GPR)41 and GPR43 in various tissues such as pancreatic islets, adipose, large intestinal tissue, immune system, and nervous system because SCFAs can penetrate the blood brain barrier.(13,36,39) In its function on the pancreatic islet, SCFAs can induce insulin secretion through Glucagon-like Peptide (GLP)-1 secretion.(40) SCFAs also increase growth and viability of beta cells by increasing the expression of receptors on pancreatic beta cells that contribute to the beta cell adaptive response to high insulin requirements in obesity.(41) In addition, in vitro experiments proved that the loss of GPR41 and GPR43 decreases the ability of beta cells to survive in the presence of SCFAs. It can be concluded that SCFAs play a major role in the survivability of beta cells (Figure 3 ) to stress due to its compensation insulin high demand in obesity.(32)

At the same time with an increase in beta cell mass and insulin secretion, SCFAs also play a role in the regulation of the immune system and control the inflammation caused by obesity. The anti-inflammatory feature possessed by SCFAs is beneficial for beta cells to survive from damage. One of the cause of pancreatic beta cell damage is inflammation

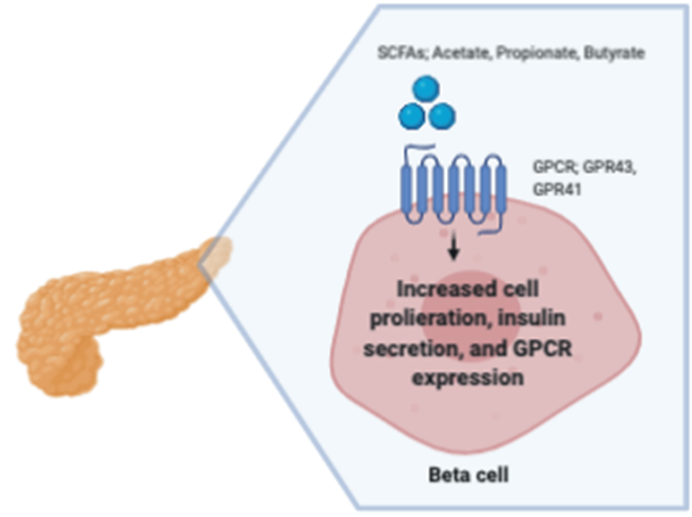

Figure 3. The role of SCFAs in beta cell proliferation and function through GPCR.

that spreads from adipose tissue to the pancreas. $(19,35,42)$ Immune system regulation facilitated by SCFAs is carried out through suppression of inflammatory effectors and differentiation of dendritic cells from hematopoietic stem cells in the bone marrow. Another regulatory mechanism of SCFAs against the immune system is by increasing the production of Regulator $\mathrm{T}$ cells (T-Reg) through HDAC inhibition and decreasing effector $\mathrm{T}$ cells such as (T Helper 17 (Th17) cells. Th17 cells are immune cells that secrete IL17 including IL-17F. $(43,44)$ On the other hand, SCFAs not only but also reduce the expression of IL-17.(45) Figure 4 show the complete features of SCFAs on beta cell health and function to maintain insulin adequacy.

Based on the role of SCFAs in beta cells, it is necessary to measure the level of SCFAs because they

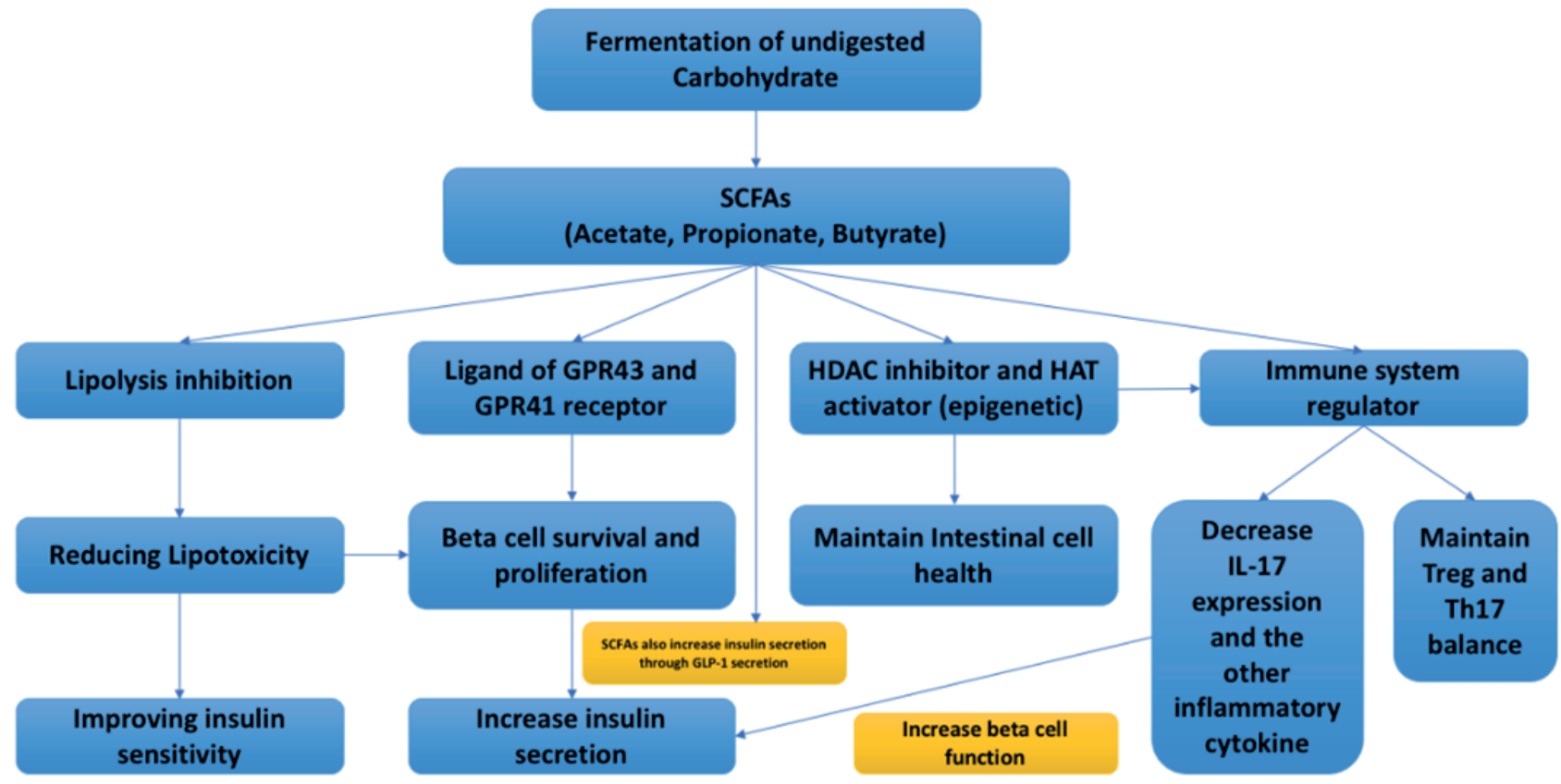

Figure 4. The complete features of SCFAs on pancreatic beta cell health and function to maintain insulin adequacy. 
already involved at the beginning of the T2DM-induced central obesity pathogenesis; inflammation and beta cell compensation mechanism. As described above, SCFAs are produced in the human intestine and commonly quantified from fecal samples. But there is still a gap how to describe SCFAs can influence certain organ as they produced in the intestine. Recent evidence showed that $95 \%$ of SCFAs are absorbed and transferred to the blood stream and finally reached the target organ as a signal molecule to affect its metabolism.(13) In addition, SCFAs are known to directly regulate the tissue and organ metabolism and also influence their specific mechanism including obesity. Because of that, SCFAs are considered as metabolic regulator.(46)

The involvements of SCFAs in many metabolic processes have generated a theory of a possible mechanistic link to the metabolic syndrome and central obesity as the main risk factors. Recent study showed that not fecal SCFAs concentration that correlated with metabolic markers such as GLP-1, fatty acid metabolism, and insulin sensitivity, but blood SCFAs did.(13) Hence, it is plausible that blood SCFAs quantification would give a good advantage in predicting beta cell failure at the early stage before the occurrence of T2DM. Furthermore, not only SCFAs that play a crucial role in the beta cell health, but also $\mathrm{Zn}$ that commonly known as essential micronutrient which is get involved in every step of insulin synthesis.(47)

\section{The Role of Zn in Beta Cell Function}

$\mathrm{Zn}$ is one of the essential elements involved in various biological processes in cells. Zn serves as a constituent structural component for many proteins and as a cofactor for various metalloenzymes. The role of $\mathrm{Zn}$ in many physiological pathways occurs in cells as well as insulin synthesis, so that intracellular Zn concentrations are higher than circulating one. Physiological negligence generally occurs due to oxidative stress which results in inflammation. $\mathrm{Zn}$ is a very important element for endogenous antioxidant enzyme cofactor, namely superoxide dismutase (SOD). This enzyme functions to neutralize superoxide produced by mitochondria during the electron transport process. Various degenerative diseases are known to originate at the root of oxidative stress, one of which is T2DM.(48)

$\mathrm{Zn}$ 's association with diabetes was identified for 70 years ago through its correlation with pancreatic beta cell function. Zn plays a role in the synthesis, transport, and modification of insulin.(47) Deficiency and abnormalities of $\mathrm{Zn}$ homeostasis will interfere with the redox potential of pancreatic islet cells resulting in failure of insulin production and secretion. The problematic redox potential will produce free radicals that cause oxidative stress.(48) Regarding to the function in the insulin synthesis, $\mathrm{Zn}$ uptake facilitated by the Zinc Transporter 8 (ZnT8) which is exclusively expressed in pancreatic beta cell vesicles. ZnT8 the genetic variation of this transporter commonly known as T2DM risk factor. $(49,50)$

Chronic inflammation that occurs in central obesity and diabetes has been linked to $\mathrm{Zn}$ concentrations. In subjects with low serum $\mathrm{Zn}$ concentration, there was an increase in the level of inflammatory cytokines such as Tumor necrosis factor (TNF)- $\alpha$, interleukin (IL)-6, and IL-1b not only in adipose tissue, but also in pancreatic islet cells which function to produce insulin.(51) The low serum $\mathrm{Zn}$ concentration is due to the high free $\mathrm{Zn}$ flux into the inflamed tissue. Chronic inflammation of the tissues results in increased glucocorticoid concentrations and the expression of metallothionein which carry $\mathrm{Zn}$ into the tissues.(52) Inflammation and damage to pancreatic beta cells can be mediated by the autoreactivity of $\mathrm{T}$ cells that induces Fas receptor expression, which implies increasing the cytotoxic sensitivity of $\mathrm{T}$ cells. This damage causes persistent perturbation of $\mathrm{Zn}$ homeostasis. $(50,52)$

$\mathrm{Zn}$ homeostasis in the human body is an unstable system with a rate of change of more than 150 times per day. The serum pool of $\mathrm{Zn}$ is about $0.1 \%$ of total $\mathrm{Zn}$ in the body and $98 \%$ is bound to serum proteins and is not ready to interact with immune cells and other tissues. Therefore, the $\mathrm{Zn}$ concentration that is considered more representative is free $\mathrm{Zn}$ in serum. In inflammatory conditions, there is a change in the strength of $\mathrm{Zn}$ bonds with serum proteins that change cell activity in response to its interaction with $\mathrm{Zn} .(48,53,54)$ Thus, it can be said that micronutrient markers such as $\mathrm{Zn}$ have many roles in the pathophysiology of inflammation, insulin resistance, beta cell failure, and T2DM

Previous study showed that there was a good correlation between serum free $\mathrm{Zn}$ with HOMA-B, the concentration of serum free $\mathrm{Zn}$ increased along with HOMA-B and indicating the excessive function of beta cells and interestingly, it reduced dramatically in T2DM along the decrease beta cell function.(55) Based on that finding, $\mathrm{Zn}$ showed a potential feature to predict beta cell failure at the early stage of chronically beta cells stress when compensate the high demand of insulin in central obesity. The complete $\mathrm{Zn}$ features in beta cell protection from oxidative stress and inflammation and insulin production illustrated in Figure 5. 


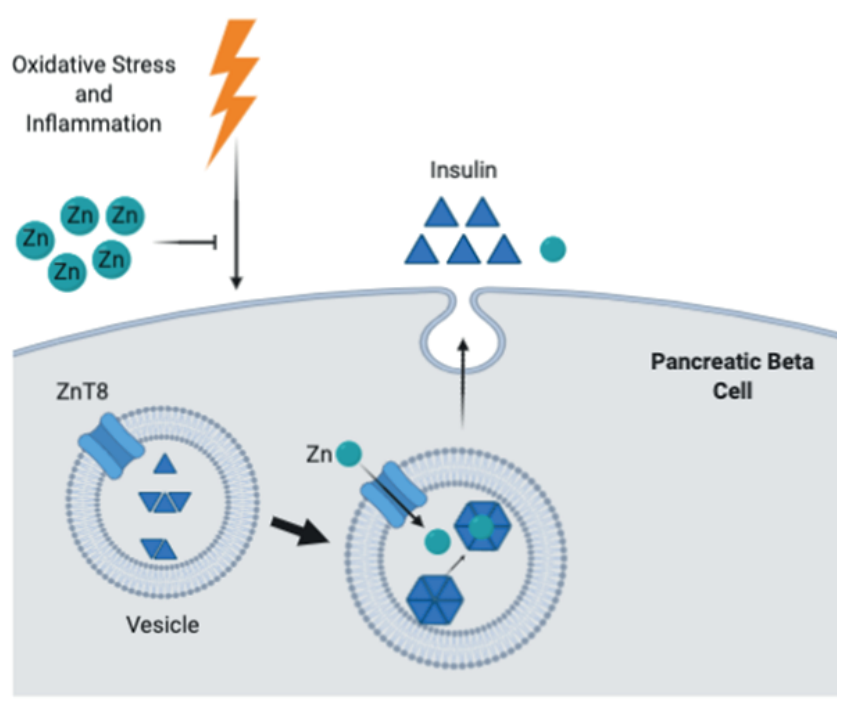

Figure 5. The complete features of $\mathrm{Zn}$ on pancreatic beta cell protection and function to maintain insulin adequacy. $\mathrm{Zn}$ has a protective effect for beta cell against oxidative stress and inflammation since it acts as cofactor for Superoxide Dismutase (SOD) and inhibit NF-KB activation. $\mathrm{Zn}$ is involved in insulin synthesis, crystallization and secretion that make it is very important for beta cell health and function.

\section{Conclusion}

The prospective features of SCFAs and $\mathrm{Zn}$ as beta cell failure early prediction tool are related to each other in central obesity. SCFAs become an emerging biomarker for T2DM because of their involvement from the beginning of the pathogenesis of disease. Moreover, $\mathrm{Zn}$ is commonly known as an essential micronutrient that play many roles in several metabolic pathways and also supporting the protection system against inflammation and oxidative stress to the beta cells. We proposed that quantification of these two nutrients in the blood expected to provide an early warning tool to maintain insulin adequacy and predict the possibility of beta cell failure in central obesity with promising performance.

\section{Authors Contribution}

All authors were involved in concepting and planning the research, MNR performed the data acquisition/collection, all authors calculated the experimental data and performed the analysis, MNR drafted the manuscript and designed the figures and assisted by MIB, MF and MB also aided in interpreting the results. All authors took parts in giving critical revision of the manuscript.

\section{References}

1. World Health Organization [Internet]. Obesity and overweight [cited 2020 Nov 6]. Available from: https://www.who.int/news-room/factsheets/detail/obesity-and-overweight.

2. James PT, Leach R, Kalamara E, Shayeghi M. The worldwide obesity epidemic. Obes Res. 2001; 9 (Suppl 4): 228S-33S.

3. Nuttall FQ. Body mass index: obesity, BMI, and health: a critical review. Nutr Today. 2015; 50: 117-28.

4. Olinto MTA, Theodoro H, Canuto R. Epidemiology of abdominal obesity. In: Gordeladze JO, editor. Adiposity - Epidemiol Treat Modalities. London: IntechOpen; 2017.

5. Wong MCS, Huang J, Wang J, Chan PSF, Lok V, Chen X, et al. Global, regional and time-trend prevalence of central obesity: a systematic review and meta-analysis of 13.2 million subjects. Eur J Epidemiol. 2020; 35: 673-83.

6. Papaetis GS, Papakyriakou P, Panagiotou TN. Central obesity, type 2 diabetes and insulin: exploring a pathway full of thorns. Arch Med Sci AMS. 2015; 11: 463-82.

7. Ohnishi H, Saitoh S, Takagi S, Katoh N, Chiba Y, Akasaka H, et al. Incidence of type 2 diabetes in individuals with central obesity in a rural Japanese population: the Tanno and Sobetsu Study. Diabetes Care. 2006; 29: 1128-9.

8. Mihardja L, Soetrisno U, Soegondo S. Prevalence and clinical profile of diabetes mellitus in productive aged urban Indonesians. J Diabetes Investig. 2014; 5: 507-12.

9. Wang C, Liu Z, Zhang P, Ma X, Che K, Wang Y, et al. The differences in homeostasis model assessment values in type 2 diabetic patients with different lengths of history of diabetes. Arch Endocrinol Metab. 2019; 63: 222-7.

10. Song I, Roels S, Martens GA, Bouwens L. Circulating microRNA-375 as biomarker of pancreatic beta cell death and protection of beta cell mass by cytoprotective compounds. PloS One. 2017; 12: e0186480. doi: 10.1371/journal.pone.0186480.

11. Song Y, Manson JE, Tinker L, Howard BV, Kuller LH, Nathan L, et al. Insulin sensitivity and insulin secretion determined by homeostasis model assessment (HOMA) and risk of diabetes in a multiethnic cohort of women: the women's health initiative observational study. Diabetes Care. 2007; 30: 1747-52.

12. Saisho Y. $\beta$-cell dysfunction: Its critical role in prevention and management of type 2 diabetes. World J Diabetes. 2015; 6: 109-24.

13. Müller M, Hernández MAG, Goossens GH, Reijnders D, Holst JJ, Jocken JWE, et al. Circulating but not faecal short-chain fatty acids are related to insulin sensitivity, lipolysis and GLP-1 concentrations in humans. Sci Rep. 2019; 9: 12515. doi: 10.1038/s41598-01948775-0.

14. WHO Expert Consultation. Appropriate body-mass index for Asian populations and its implications for policy and intervention strategies. Lancet Lond Engl. 2004; 363: 157-63.

15. Castro AVB, Kolka CM, Kim SP, Bergman RN. Obesity, insulin resistance and comorbidities - Mechanisms of association. Arq Bras Endocrinol Metabol. 2014; 58: 600-9.

16. Guebre-Egziabher F, Alix PM, Koppe L, Pelletier CC, Kalbacher E, Fouque D, et al. Ectopic lipid accumulation: A potential cause for metabolic disturbances and a contributor to the alteration of kidney function. Biochimie. 2013; 95: 1971-9.

17. Tulloch-Reid MK, Hanson RL, Sebring NG, Reynolds JC, Premkumar A, Genovese DJ, et al. Both subcutaneous and visceral adipose tissue correlate highly with insulin resistance in african americans. Obes Res. 2004; 12: 1352-9. 
18. International Obesity Task Force. The Asia Pacific Perspective: Redifining Obesity and Its Treatment. Sydney: Health Communications Australia; 2000.

19. Item F, Konrad D. Visceral fat and metabolic inflammation: the portal theory revisited. Obes Rev Off J Int Assoc Study Obes. 2012;13 (Suppl 2): 30-9.

20. Morigny P, Houssier M, Mouisel E, Langin D. Adipocyte lipolysis and insulin resistance. Biochimie. 2016; 125: 259-66.

21. Ye J, McGuinness OP. Inflammation during obesity is not all bad: evidence from animal and human studies. Am J Physiol Endocrinol Metab. 2013; 304: E466-77.

22. Meiliana A, Wijaya A. Metaflammation, NLRP3 Inflammasome, Obesity and Metabolic Disease. Indones Biomed J. 2011; 3: $168-84$.

23. Brereton MF, Rohm M, Ashcroft FM. $\beta$-Cell dysfunction in diabetes: a crisis of identity? Diabetes Obes Metab. 2016; 18 (Suppl 1): 102-9.

24. Cerf ME. Beta cell dysfunction and insulin resistance. Front Endocrinol. 2013; 4: 37. doi: 10.3389/fendo.2013.00037.

25. Ashcroft FM, Rorsman P. Diabetes mellitus and the $\beta$ cell: the last ten years. Cell. 2012; 148: 1160-71.

26. Butler AE, Dhawan S. $\beta$-Cell identity in type 2 diabetes: lost or found? Diabetes. 2015; 64: 2698-700.

27. Templeman NM, Skovsø S, Page MM, Lim GE, Johnson JD. A causal role for hyperinsulinemia in obesity. J Endocrinol. 2017; 232: R173-83.

28. Indonesian Diabetes Association. Guidelines on the management and prevention of prediabetes. Acta Medica Indones. 2014; 46: 348-59.

29. Kim $\mathrm{CH}$. Microbiota or short-chain fatty acids: which regulates diabetes? Cell Mol Immunol. 2018; 15: 88-91.

30. Liu JL, Segovia I, Yuan X-L, Gao Z. Controversial roles of gut microbiota-derived short-chain fatty acids (SCFAs) on pancreatic $\beta$-Cell growth and insulin secretion. Int J Mol Sci. 2020; 21: 910. doi: 10.3390/ijms21030910.

31. Priyadarshini M, Wicksteed B, Schiltz GE, Gilchrist A, Layden BT. SCFA receptors in pancreatic $\beta$ cells: novel diabetes targets? Trends Endocrinol Metab. 2016; 27: 653-64.

32. Koh A, De Vadder F, Kovatcheva-Datchary P, Bäckhed F. From dietary fiber to host physiology: short-chain fatty acids as key bacterial metabolites. Cell. 2016; 165: 1332-45.

33. Ding R, Goh WR, Wu R, Yue X, Luo X, Khine WWT, et al. Revisit gut microbiota and its impact on human health and disease. J Food Drug Anal. 2019; 27: 623-31.

34. Heimann E, Nyman M, Degerman E. Propionic acid and butyric acid inhibit lipolysis and de novo lipogenesis and increase insulinstimulated glucose uptake in primary rat adipocytes. Adipocyte. 2014; 4: 81-8.

35. Li X, Shimizu Y, Kimura I. Gut microbial metabolite short-chain fatty acids and obesity. Biosci Microbiota Food Health. 2017; 36: 135-40.

36. den Besten G, van Eunen K, Groen AK, Venema K, Reijngoud DJ, Bakker BM. The role of short-chain fatty acids in the interplay between diet, gut microbiota, and host energy metabolism. J Lipid Res. 2013; 54: 2325-40.

37. Wei JW, Huang K, Yang C, Kang CS. Non-coding RNAs as regulators in epigenetics. Oncol Rep. 2017; 37: 3-9.

38. Fellows R, Denizot J, Stellato C, Cuomo A, Jain P, Stoyanova E, et al. Microbiota derived short chain fatty acids promote histone crotonylation in the colon through histone deacetylases. Nat
Commun. 2018; 9: 105. doi: 10.1038/s41467-017-02651-5.

39. Pingitore A, Chambers ES, Hill T, Maldonado IR, Liu B, Bewick G, et al. The diet-derived short chain fatty acid propionate improves beta-cell function in humans and stimulates insulin secretion from human islets in vitro. Diabetes Obes Metab. 2017; 19: 257-65.

40. Bilotta AJ, Cong Y. Gut microbiota metabolite regulation of host defenses at mucosal surfaces: implication in precision medicine. Precis Clin Med. 2019; 2: 110-9.

41. Villa SR, Priyadarshini M, Fuller MH, Bhardwaj T, Brodsky MR, Angueira AR, et al. Loss of free fatty acid receptor 2 leads to impaired islet mass and beta cell survival. Sci Rep. 2016; 6: 28159. doi: $10.1038 /$ srep28159.

42. Li M, van Esch BCAM, Wagenaar GTM, Garssen J, Folkerts G, Henricks PAJ. Pro- and anti-inflammatory effects of short chain fatty acids on immune and endothelial cells. Eur J Pharmacol. 2018; 831: 52-9.

43. Korn T, Bettelli E, Oukka M, Kuchroo VK. IL-17 and Th17 cells. Annu Rev Immunol. 2009; 27: 485-517.

44. Chang PV, Hao L, Offermanns S, Medzhitov R. The microbial metabolite butyrate regulates intestinal macrophage function via histone deacetylase inhibition. Proc Natl Acad Sci USA. 2014; 111: 2247-52.

45. Asarat M, Apostolopoulos V, Vasiljevic T, Donkor O. Short-chain fatty acids regulate cytokines and Th17/Treg cells in human peripheral blood mononuclear cells in vitro. Immunol Invest. 2016; 45: 205-22.

46. Chambers ES, Preston T, Frost G, Morrison DJ. Role of gut microbiota-generated short-chain fatty acids in metabolic and cardiovascular health. Curr Nutr Rep. 2018; 7: 198-206.

47. Meyer JA, Spence DM. A perspective on the role of metals in diabetes: past findings and possible future directions. Metallomics. 2009; 1: 32-41.

48. Rutter GA, Chabosseau P, Bellomo EA, Maret W, Mitchell RK, Hodson DJ, et al. Intracellular zinc in insulin secretion and action: a determinant of diabetes risk? Proc Nutr Soc. 2016; 75: 61-72.

49. Huang Q, Du J, Merriman C, Gong Z. Genetic, functional, and immunological study of ZnT8 in diabetes. Int J Endocrinol. 2019; 2019: 1524905. doi: 10.1155/2019/1524905.

50. Giacconi R, Malavolta M, Chiodi L, Boccoli G, Costarelli L, Bonfigli AR, et al. ZnT8 Arg325Trp polymorphism influences zinc transporter expression and cytokine production in PBMCs from patients with diabetes. Diabetes Res Clin Pract. 2018; 144: $102-10$.

51. Foster M, Samman S. Zinc and regulation of inflammatory cytokines: implications for cardiometabolic disease. Nutrients. 2012; 4: 676-94.

52. Martins LM, Oliveira ARS de, Cruz KJC, Nogueira N do N, Marreiro $\mathrm{D}$ do $\mathrm{N}$, Araújo CGB de, et al. Influence of cortisol on zinc metabolism in morbidly obese women. Nutr Hosp. 2014; 29: 57-63.

53. Donath MY, Størling J, Maedler K, Mandrup-Poulsen T. Inflammatory mediators and islet beta-cell failure: a link between type 1 and type 2 diabetes. J Mol Med Berl Ger. 2003; 81: 455-70.

54. Hoeger J, Simon TP, Doemming S, Thiele C, Marx G, Schuerholz T, et al. Alterations in zinc binding capacity, free zinc levels and total serum zinc in a porcine model of sepsis. Biometals Int J Role Met Ions Biol Biochem Med. 2015; 28: 693-700.

55. Rahman MN, Sukmawati IR, Puspitasari IM, Fattah M. Serum free zinc as a predictor for excessive function of pancreatic beta-cells in central-obese men. Indones Biomed J. 2019; 11: 262-6. 